LUNG CANCER

\title{
Lung cancer and air pollution: a 27 year follow up of 16209 Norwegian men
}

\author{
P Nafstad, L L Håheim, B Oftedal, F Gram, I Holme, I Hjermann, P Leren
}

Thorax 2003;58:1071-1076

See end of article for authors' affiliations .....................

Correspondence to: Dr Per Nafstad, Division of Epidemiology, Norwegian Institute of Public Health, PO Box 4404 Nydalen, 0403 Oslo, Norway; per.nafstad@fhi.no

Received 8 March 2003 Accepted for publication 19 June 2003

\begin{abstract}
Background: The well documented urban/rural difference in lung cancer incidence and the detection of known carcinogens in the atmosphere have produced the hypothesis that long term air pollution may have an effect on lung cancer. The association between incidence of lung cancer and long term air pollution exposure was investigated in a cohort of Oslo men followed from 1972/73 to 1998.

Methods: Data from a follow up study on cardiovascular risk factors among 1620940 to 49 year old Oslo men in 1972/73 were linked to data from the Norwegian cancer register, the Norwegian death register, and estimates of average yearly air pollution levels at the participants' home address in 1974 to 1998. Survival analyses, including Cox proportional hazards regression, were used to estimate associations between exposure and the incidence of lung cancer.

Results: During the follow up period, 418 men developed lung cancer. Controlling for age, smoking habits, and length of education, the adjusted risk ratio for developing lung cancer was $1.08195 \%$ confidence interval, 1.02 to 1.15 ) for a $10 \mu \mathrm{g} / \mathrm{m}^{3}$ increase in average home address nitrogen oxide $\left(\mathrm{NO}_{\mathrm{x}}\right)$ exposure between 1974 and 1978. Corresponding figures for a $10 \mu \mathrm{g} / \mathrm{m}^{3}$ increase in sulphur dioxide $\left(\mathrm{SO}_{2}\right)$ were 1.01 (0.94 to 1.08$)$.

Conclusions: Urban air pollution may increase the risk of developing lung cancer.
\end{abstract}

T he acute or short time health effects of urban air pollution have been explored in a large number of time series studies, but few have been able to address the chronic health effects of long term exposure to air pollution. In this perspective, lung cancer is one of the health end points of particular interest. ${ }^{1-7}$ Lung cancer is evidently a disease affected by environmental exposure. ${ }^{8-10}$ Urban air contains carcinogens, ${ }^{45}$ and urban/rural risk differences in lung cancer cannot be fully explained by differences in tobacco smoke exposure. ${ }^{9}$ This could indicate that other urban exposures are important.

The association between urban air pollution and lung cancer is difficult to study. ${ }^{711} \mathrm{~A}$ major challenge has been the assessment of individual long term air pollution exposure in prospective cohort studies. Most studies of air pollution and cancer have assessed long term air pollution exposure on an aggregated (non-individual) level. $^{712-18}$ The use of geographical information systems is a relatively new approach for assessing long term individual exposure in epidemiological studies. ${ }^{19-26}$ In this study we used a similar approach to estimate residential ambient air pollution from 1974 to 1998 for a cohort of 16209 men living in Oslo, Norway. The information was linked to information on cancer development from the Norwegian cancer register in order to estimate associations between long term exposure to outdoor air pollutants and the development of lung cancer.

\section{METHODS}

\section{Study population}

The study population consisted of 16209 of a total of 25915 Oslo men aged 40 to 49 years old who agreed in 1972 to participate in a population based follow up study of cardiovascular diseases. The participants all met for a one day screening investigation between May 1972 and December 1973. The invitation to participate included a questionnaire, which the participants were instructed to fill in and bring with them to the screening investigation..$^{27}$

\section{Health outcome}

The Norwegian cancer register includes information on all persons with cancer in Norway. The register is considered accurate and almost complete. ${ }^{29}$ Participants receiving International Classification of Disease (ICD), version 7, codes 140 to 207 in the Norwegian cancer register during the follow up period of this study were included as having cancer, and those receiving ICD-7 codes 162.1 to 162.9 as having lung cancer. The national death register (the National Bureau of Statistics) provided data on all deaths within the cohort, including the cause of death in ICD-8/ICD-9/ICD-10 codes. Both registers were updated through 1998.

\section{Exposure assessment}

The Norwegian Institute for Air Research (NILU) has estimated average concentrations of air pollutants per year at the home address of all participants from 1974 to $1995 .^{30}$

For sulphur dioxide $\left(\mathrm{SO}_{2}\right)$ the model is based upon detailed model calculations for the years 1979 and $1998 .^{31}{ }^{32}$ For the other years the concentrations were calculated using data for observed concentrations and emission from point sources (industry and heating of buildings and private homes) and traffic. We thus calculated separate fields with yearly averages for $\mathrm{SO}_{2}$ for each $\mathrm{km}^{2}$ from heating and traffic for each year during the period 1974 to 1995 . For nitrogen oxides $\left(\mathrm{NO}_{\mathrm{x}}\right)$, observed concentrations were not available for all the years and a new procedure was developed. The $\mathrm{SO}_{2}$ fields were first divided by the emissions from heating and traffic, respectively, to give two sets with annual dispersion fields, and these fields were multiplied by the annual emissions of $\mathrm{NO}_{\mathrm{x}}$. The shape of the concentration fields was given from the model calculations, and the level of the fields from the measurements. The dispersion fields tell about the dispersion conditions for each year, and are multiplied by annual emissions to give annual concentration fields. Indicators for exposure to particulate matter and lead were also estimated, but because of small variations in exposure levels and strong 
correlation with $\mathrm{SO}_{2}$ exposure these components were not considered in the analyses.

Average air pollution exposure at the home address was estimated for each person each year from 1974 to 1998. The national population register provided updated information on home addresses. A person moving within Oslo was given the average air pollutant concentration at the address he lived in the largest part of that year. The information was linked to map references. Addresses linked to 50 of the busiest streets were given an additional exposure based on vehicle counts. Persons moving from Oslo were treated in a special way. Concentration data only exist for the largest cities in Norway. These data and measurements of background exposure levels were used to estimate an average concentration index for 20 different regions. Each postal code was assigned to one of the regions, and the concentration for one specific year was calculated as the region concentration multiplied by an emission index for the year. The calculated values were used to estimate each participant's average home address exposure for different time windows and cumulative exposures. Persons moving abroad or to regions where such calculation was impossible were considered lost to follow up.

\section{Covariates}

Information on most covariates is based on the baseline screening of the cohort. ${ }^{27} 28$ The following information was used in the current analyses: age, smoking habits, physical activity, occupation, height, and weight. The National Bureau of Statistics provided information on highest level of education. Categorisation of the main covariates is presented in table 1.

\section{Statistical methods}

The incidence of lung cancer was calculated per 1000 observational years. Cox proportional hazard regression models were used to evaluate the association between the incidence of cancer and selected indicators of air pollution. For the analyses of time to lung cancer, each participant's observation time was censored at the year when the person was diagnosed as having other types of cancer, died, emigrated, moved to an address without information on air pollution exposure, or at the end of the follow up. Air pollution levels were included as both continuous and categorical variables. As it turned out, the average exposure levels were skewed, with little variation in the lower quartiles (range within first to second quartile: $\mathrm{NO}_{\mathrm{x}}, 0$ to $11 \mu \mathrm{g} / \mathrm{m}^{3}$; $\mathrm{SO}_{2}, 0$ to $9 \mu \mathrm{g} / \mathrm{m}^{3}$ ). The exposure levels were therefore grouped as follows: 0 to $9.99,10.00$ to $19.99,20.00$ to 29.99 , and above $30.00 \mu \mathrm{g} / \mathrm{m}^{3}$. To study the functional form of air pollution exposure, continuous exposures were also modelled as smoothed cubic splines with four degrees of freedom, using the program S-PLUS. ${ }^{33}{ }^{34}$ All registered covariates were evaluated in the Cox proportional hazard model for inclusion in the final statistical model, one at a time. The criterion for inclusion in the final model was that the precision of the model significantly $(p<0.05)$ increased according to the loglikelihood test. The final model included education, age at inclusion, and smoking habits.

The main focus was on air pollution exposure the first five years of the follow up. Analyses with yearly averages and with later five year periods were done as well, but are not presented. $\mathrm{NO}_{\mathrm{x}}$ and $\mathrm{SO}_{2}$ were also treated as time dependent variables in the Cox regression models. Each time a risk set was created for a new lung cancer case, the cumulated air pollutant variable for each individual in the risk set was recomputed as the sum of the yearly exposures from 1974 through the following years, stopping three years before the year with the diagnosis of the defining case. In addition to the previously described three year lag time between time dependent cumulative exposure and lung cancer, no lag time was also tried in the analyses. We also specified a model with average exposure for the years 1974 to 1978 and a time dependent variable for cumulative exposure after 1978 in order to look for excess risk from exposure after 1978.

\section{RESULTS}

Of the 16209 men included in the study, 2892 (17.9\%) had been registered in the Norwegian cancer register as having developed cancer during the follow up, and $422(2.6 \%)$ were registered as having developed lung cancer. Persons registered with cancer before the screening had ended were excluded. Included in the analyses were 418 (2.0\%) with lung

Table 1 Age, levels of education, type of occupation and smoking habits among 16209 middle aged Oslo men according to five years average nitrogen oxides $\left(\mathrm{NO}_{x}\right)$ exposure at their home addresses, 1974 to 1978

\begin{tabular}{|c|c|c|c|c|c|}
\hline & \multirow[b]{2}{*}{$\mathrm{N}$} & \multicolumn{4}{|c|}{$\mathrm{NO}_{x}$ exposure $\left(\mu \mathrm{g} / \mathrm{m}^{3}\right)$} \\
\hline & & $\begin{array}{l}0-9.99 \\
(n=6474)\end{array}$ & $\begin{array}{l}10-19.99 \\
(n=4479)\end{array}$ & $\begin{array}{l}20-29.99 \\
(n=3082)\end{array}$ & $\begin{array}{l}30+ \\
(n=1931)\end{array}$ \\
\hline $\begin{array}{l}\text { Total } \\
\text { Age }\end{array}$ & 15966 & $40.5 \%$ & $28.1 \%$ & $19.3 \%$ & $12.1 \%$ \\
\hline 40 to 45 years & 7308 & $41.5 \%$ & $27.4 \%$ & $17.7 \%$ & $13.4 \%$ \\
\hline $\begin{array}{l}46 \text { to } 49 \text { years } \\
\text { Education }\end{array}$ & 8658 & $39.7 \%$ & $28.6 \%$ & $20.7 \%$ & $11.0 \%$ \\
\hline$<10$ years & 4761 & $39.1 \%$ & $28.1 \%$ & $22.8 \%$ & $9.9 \%$ \\
\hline 10 to 12 years & 7726 & $42.5 \%$ & $27.4 \%$ & $17.8 \%$ & $12.3 \%$ \\
\hline $12+$ years & 3443 & $38.3 \%$ & $29.4 \%$ & $17.7 \%$ & $14.6 \%$ \\
\hline $\begin{array}{l}\text { Occupation } \\
\text { "Blue collar" }\end{array}$ & & & & & \\
\hline Moderate physical work & 4678 & $41.6 \%$ & $27.8 \%$ & $17.8 \%$ & $12.7 \%$ \\
\hline Intermediate physical work & 2736 & $40.6 \%$ & $27.7 \%$ & $20.0 \%$ & $11.8 \%$ \\
\hline Vigorous physical work & 592 & $38.8 \%$ & $29.3 \%$ & $20.8 \%$ & $11.1 \%$ \\
\hline $\begin{array}{l}\text { "White collar" } \\
\text { Smoking habits }\end{array}$ & 7812 & $37.5 \%$ & $29.9 \%$ & $22.0 \%$ & $10.6 \%$ \\
\hline $\begin{array}{l}\text { Smoking habits } \\
\text { Non-smoker }\end{array}$ & 3031 & $42.0 \%$ & $28.7 \%$ & $17.2 \%$ & $12.2 \%$ \\
\hline 1-9 cigarettes per day & 1543 & $42.1 \%$ & $26.9 \%$ & $19.4 \%$ & $11.6 \%$ \\
\hline 10-19 cigarettes per day & 4361 & $39.0 \%$ & $28.0 \%$ & $21.4 \%$ & $11.5 \%$ \\
\hline $20+$ cigarettes per day & 3007 & $37.0 \%$ & $28.2 \%$ & $21.9 \%$ & $12.9 \%$ \\
\hline Smoker, amount not reported & 75 & $44.0 \%$ & $28.0 \%$ & $9.3 \%$ & $18.7 \%$ \\
\hline Former smoker & 3949 & $43.2 \%$ & $28.0 \%$ & $16.7 \%$ & $12.1 \%$ \\
\hline
\end{tabular}


cancer and 2384 (14.7\%) with other cancers (incidence rates 6.77 (95\% confidence interval (CI), 6.50 to 7.04 ) and 1.19 ( 1.07 to 1.30 ) per 1000/year, respectively). Average time to diagnosis of cancer was 15.8 years and for lung cancer, 16.1 years. The lung cancer incidence was 0.94 (0.79 to 1.09 ) among men 40 to 45 years old at inclusion, and 1.41 ( 1.24 to 1.58) among those who were 46 to 49 years old.

Figure 1 shows the yearly average levels of $\mathrm{SO}_{2}$ and $\mathrm{NO}_{\mathrm{x}}$ at the home addresses of the participants in the cohort. $\mathrm{SO}_{2}$ levels were reduced by a factor of 7 during the study period, while no such reduction was seen for $\mathrm{NO}_{\mathrm{x}}$. Air pollution exposure varied considerably within the cohort. The five year median average levels of exposure at the participants' home address during 1974 to 1978 were $10.7 \mu \mathrm{g} / \mathrm{m}^{3}$ (range 0.7 to $168.3 \mu \mathrm{g} / \mathrm{m}^{3}$ ) for $\mathrm{NO}_{\mathrm{x}}$ and $9.4 \mu \mathrm{g} / \mathrm{m}^{3}$ (range 0.2 to $55.8 \mu \mathrm{g}$ / $\mathrm{m}^{3}$ ) for $\mathrm{SO}_{2}$. Median levels within the quartiles of $\mathrm{NO}_{\mathrm{x}}$ exposure were $3.8,9.3,15.4$, and $28.8 \mu \mathrm{g} / \mathrm{m}^{3}$, and for $\mathrm{SO}_{2}, 2.5$, $6.2,14.7$, and $31.3 \mu \mathrm{g} / \mathrm{m}^{3}$. The correlation between $\mathrm{NO}_{\mathrm{x}}$ and $\mathrm{SO}_{2}$ was 0.63 (95\% CI 0.62 to 0.64 ) (Pearson's correlation coefficient).

Table 1 presents age groups, education level, type of occupation, and smoking habits and the distribution of these conditions according to level of $\mathrm{NO}_{\mathrm{x}}$ exposure at their home addresses during 1974 to 1978. Most of the participants had sedentary work, and only $21 \%(17.3 \%+3.7 \%)$ had intermediate or vigorous physical activity during work hours. Education level was high $(70 \%$ with 10 or more years of education) and a large proportion of the participants reported that they were smokers or former smokers $(56.3 \%$ current smokers, $24.7 \%$ former smokers). $\mathrm{NO}_{\mathrm{x}}$ exposure in 1974 to 1978 was quite evenly distributed according to education level, type of occupation, and former and current smoking habits. Smoking increased the risk of developing lung cancer strongly, while high education had a protective effect (table 2). The association between lung cancer and type of work was substantially weakened when the other covariates were controlled for.

Table 3 shows the incidence of lung cancer according to five year (1974 to 1978) average levels of air pollutants at the participants' home addresses, and the risk ratios in different intervals of exposure and as a $10 \mu \mathrm{g} / \mathrm{m}^{3}$ continuous increase in exposure. Having a five year $\mathrm{NO}_{\mathrm{x}}$ exposure in 1974 to 1978 of above $30 \mu \mathrm{g} / \mathrm{m}^{3}$ increased the risk of developing lung cancer compared with exposure of less than $10 \mu \mathrm{g} / \mathrm{m}^{3}$. The association was further explored in a spline showing the dose-response relation between risk of lung cancer and $\mathrm{NO}_{\mathrm{x}}$ (fig 2). There was a monotonic increase in risk for exposure levels below $80 \mu \mathrm{g} / \mathrm{m}^{3}$. For the highest levels $\left(>50 \mu \mathrm{g} / \mathrm{m}^{3}\right)$

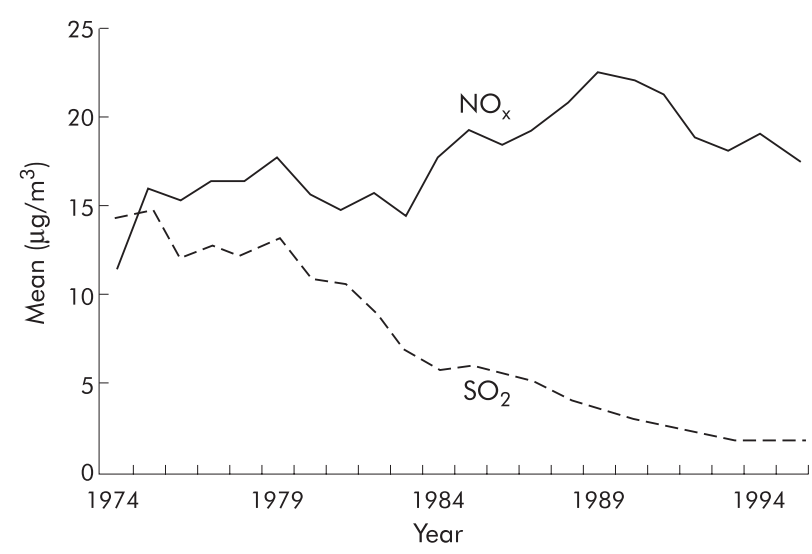

Figure 1 Mean yearly estimated concentration of sulphur dioxide $\left(\mathrm{SO}_{2}\right)$ and nitrogen oxides $\left(\mathrm{NO}_{\mathrm{x}}\right)$ at the home address of the members of the cohort. there were few observations $(\mathrm{n}=82)$ and the estimates became imprecise, with wide confidence limits. If $\mathrm{NO}_{\mathrm{x}}$ was included in the model as a continuous variable there was a significantly increased risk of lung cancer per $10 \mu \mathrm{g} / \mathrm{m}^{3}$ increase in $\mathrm{NO}_{\mathrm{x}}$ exposure (adjusted risk ratio (aRR) 1.08; 95\% CI 1.02 to 1.15 ). Excluding the highest $\mathrm{NO}_{\mathrm{x}}$ levels from the analyses gave quite similar risk estimates (not shown). Similar associations were not seen between lung cancer and $\mathrm{SO}_{2}$ exposure.

The association between lung cancer and $\mathrm{NO}_{\mathrm{x}}$ exposure at home was further explored using more recent air pollution exposures. The association became weaker when exposure from more recent five year periods was used in the analyses (not shown). A model including both $\mathrm{NO}_{\mathrm{x}}$ and $\mathrm{SO}_{2}$ in 1974 to 1978 increased the association between $\mathrm{NO}_{\mathrm{x}}$ and lung cancer somewhat. Other cancers were not significantly associated with air pollution in the one pollutant models, but the association became significant with $\mathrm{NO}_{\mathrm{x}}$ as a continuous variable in the two pollutant model.

The effect of $\mathrm{NO}_{\mathrm{x}}$ exposure was evident in different strata of smoking (table 4). Two of the strata (non-smokers and smokers, unknown amount) included few events of lung cancer and created some problems in the regression analyses. Cox regression with time dependent cumulative $\mathrm{NO}_{\mathrm{x}}$ exposure starting in 1974 with a three year lag time increased the risk of lung cancer (aRR 1.04 (95\% CI, 1.00 to 1.09 ) per cumulative increase of $100 \mu \mathrm{g} / \mathrm{m}^{3} \mathrm{NO}_{\mathrm{x}}$ per year). Corresponding figures for $\mathrm{SO}_{2}$ were 1.00 (0.94 to 1.07). Cox regression with cumulative $\mathrm{NO}_{\mathrm{x}}$ exposure starting in 1979 as a time dependent variable in addition to $\mathrm{NO}_{\mathrm{x}}$ exposure in 1974 to 1978 did not increase the risk of lung cancer further (data not shown).

\section{DISCUSSION}

The five year average home address $\mathrm{NO}_{\mathrm{x}}$ exposure in the period 1974 to 1978 was associated with an increased risk of developing lung cancer. This was also the case when $\mathrm{NO}_{\mathrm{x}}$ exposure was included in the model as a cumulative time dependent variable. The association was robust for adjustment for age, tobacco smoke exposure, and indicators of socioeconomic conditions, and was in accordance with the unexplained urban/rural risk difference in lung cancer in Norway ${ }^{9}$ and with other ecological comparisons and reviews of environmental risk factors of lung cancer. ${ }^{3467}$ A similar association was not seen between lung cancer and $\mathrm{SO}_{2}$ exposure.

Our understanding of the relation between urban air pollution and lung cancer has mostly been based on ecological or semiecological studies, ${ }^{72-18}$ and few studies have so far tried to assess long term air pollution exposure on an individual level. ${ }^{11}{ }^{21-23}$ Compared with earlier studies the current one has several strengths. The study had a longitudinal design with a large number of observational years and more than 400 cases of lung cancer in the analyses. The study population lived within one city, avoiding the possibility of between-city heterogeneity. The risk of developing lung cancer varies with age, but a large population of 40 to 49 year old men makes it easy to control for age effects. Furthermore, the study has valid information on the development of cancer, death, emigration, and changes of residence, and the outcome was lung cancer and not death from lung cancer, as in most cohort studies. Information on covariates and potential confounders was collected at the baseline screening, ensuring no reporting bias and a plausible relation in time between exposure and disease development. Air pollution exposure was estimated independently from the information on covariates, potential confounding variables, and outcome. Systematic error in home address exposure related to the outcome is therefore unlikely. 
Table 2 The crude and adjusted risk ratios with 95\% confidence intervals of developing lung cancer among 16209 middle aged men living in Oslo in 1972, according to level of education, type of occupation, and smoking habits

\begin{tabular}{|c|c|c|c|c|c|}
\hline & $\begin{array}{l}\text { Incidence } \\
\text { (1000/year) }\end{array}$ & cRR & $95 \% \mathrm{Cl}$ & *aRR & $95 \% \mathrm{Cl}$ \\
\hline \multicolumn{6}{|l|}{ Education } \\
\hline$<10$ years & 1.87 & 1 (ref) & & 1 (ref) & \\
\hline $10-12$ years & 1.03 & 0.54 & 0.44 to 0.66 & 0.67 & 0.54 to 0.82 \\
\hline $12+$ years & 0.67 & 0.35 & 0.25 to 0.47 & 0.52 & 0.38 to 0.71 \\
\hline \multicolumn{6}{|l|}{ Occupation } \\
\hline "White collar" & 0.90 & 1 (ref) & & 1 (ref) & \\
\hline \multicolumn{6}{|l|}{ "Blue collar" } \\
\hline Moderate physical work & 1.33 & 1.50 & 1.19 to 1.87 & 1.27 & 1.00 to 1.62 \\
\hline Intermediate physical work & 1.70 & 1.92 & 1.50 to 2.47 & 1.25 & 0.94 to 1.65 \\
\hline \multicolumn{5}{|l|}{ Smoking habits } & 0.68 to 1.80 \\
\hline Non-smoker & 0.08 & 1 (ref) & & 1 (ref) & \\
\hline 1-9 cigarettes per day & 0.98 & 11.90 & 4.98 to 28.37 & 11.07 & 4.31 to 28.40 \\
\hline 10-19 cigarettes per day & 1.85 & 23.03 & 10.20 to 51.88 & 22.86 & 9.43 to 55.40 \\
\hline $20+$ cigarettes per day & 2.79 & 35.23 & 15.61 to 79.50 & 36.47 & 15.06 to 88.29 \\
\hline Smoker, amount not reported & 0.57 & 6.85 & 0.82 to 56.90 & 7.95 & 0.93 to 67.90 \\
\hline Former smoker & 0.35 & 4.24 & 1.77 to 10.14 & 4.58 & 1.79 to 11.71 \\
\hline
\end{tabular}

There was no sign that the associations between air pollution and lung cancer were confounded by conditions like education, type of occupation, or smoking. However, rest confounding can never be totally excluded in observational studies. The type of occupation may, for instance, not fully capture occupational exposure to carcinogens. However, this was not a likely cause of unmeasured confounding, as vigorously active blue collar workers probably represent the main occupations at increased risk of cancer related exposures, and they were not exposed to high levels of air

\begin{tabular}{|c|c|c|c|c|c|c|c|}
\hline & \multirow{2}{*}{\multicolumn{2}{|c|}{$\begin{array}{l}\text { Incidence } \\
\text { (1000/year) cRR }\end{array}$}} & \multirow[b]{2}{*}{$95 \% \mathrm{Cl}$} & \multicolumn{2}{|c|}{ One pollutant } & \multicolumn{2}{|c|}{${ }^{*}$ Two pollutants } \\
\hline & & & & aRR & $95 \% \mathrm{Cl}$ & aRR & $95 \% \mathrm{Cl}$ \\
\hline \multicolumn{8}{|l|}{ Lung cancer } \\
\hline Model $1, \mathrm{NO}_{x_{3}}$ & & & & & & & \\
\hline $\begin{array}{l}0-9.99 \mu \mathrm{g} / \mathrm{m}^{3} \\
10-19.99 \mathrm{ug} / \mathrm{m}^{3}\end{array}$ & $\begin{array}{l}1.09 \\
1.05\end{array}$ & $\begin{array}{l}1 \text { (ref) } \\
0.96\end{array}$ & 0.75 to 1.23 & 0.90 & 0.70 to 1.15 & 1.02 & 0.75 to 1.39 \\
\hline $20-29.99 \mu \mathrm{g} / \mathrm{m}^{3}$ & 1.34 & 1.25 & 0.96 to 1.62 & 1.06 & 0.81 to 1.38 & 1.33 & 0.87 to 2.04 \\
\hline $30+\mu \mathrm{g} / \mathrm{m}^{3}$ & 1.49 & 1.37 & 1.02 to 1.85 & 1.36 & 1.01 to 1.83 & 2.22 & 1.30 to 3.79 \\
\hline Model $2, \mathrm{NO}_{x}$ & & & & & & & \\
\hline $\begin{array}{l}\text { Per } 10 \mu \mathrm{g} / \mathrm{m}^{3} \\
\text { Model } 1, \mathrm{SO}_{2}\end{array}$ & & 1.12 & 1.05 to 1.20 & 1.08 & 1.02 to 1.15 & 1.10 & 1.03 to 1.17 \\
\hline $0-9.99 \mu \mathrm{g} / \mathrm{m}^{3}$ & 1.13 & 1 (ref) & & & & & \\
\hline $10-19.99 \mu \mathrm{g} / \mathrm{m}^{3}$ & 1.28 & 1.15 & 0.89 to 1.48 & 1.05 & 0.81 to 1.35 & 0.84 & 0.57 to 1.23 \\
\hline $20-29.99 \mu \mathrm{g} / \mathrm{m}^{3}$ & 1.26 & 1.12 & 0.84 to 1.49 & 0.95 & 0.72 to 1.27 & 0.78 & 0.53 to 1.16 \\
\hline $30+\mu \mathrm{g} / \mathrm{m}^{3}$ & 1.14 & 1.01 & 0.75 to 1.36 & 1.06 & 0.79 to 1.43 & 0.56 & 0.33 to 0.95 \\
\hline $\begin{array}{l}\text { Model 2, } \mathrm{SO}_{2} \\
\quad \mathrm{Per} 10 \mu \mathrm{g} / \mathrm{m}^{3}\end{array}$ & & 1.01 & 0.94 to 1.08 & 1.01 & 0.94 to 1.08 & 0.96 & 0.88 to 1.04 \\
\hline \multicolumn{8}{|l|}{ Non-lung cancer } \\
\hline $\begin{array}{l}\text { Model } 1, \mathrm{NO}_{x} \\
0-9.99 \mu \mathrm{g} / \mathrm{m}^{3}\end{array}$ & 6.66 & & & & & & \\
\hline $10-19.99 \mu \mathrm{g} / \mathrm{m}^{3}$ & 6.65 & 1.00 & 0.91 to 1.10 & 0.98 & 0.88 to 1.08 & 1.04 & 0.92 to 1.18 \\
\hline $20-29.99 \mu \mathrm{g} / \mathrm{m}^{3}$ & 7.22 & 1.11 & 0.99 to 1.23 & 1.05 & 0.94 to 1.18 & 1.15 & 0.97 to 1.37 \\
\hline $30+\mu \mathrm{g} / \mathrm{m}^{3}$ & 6.78 & 1.03 & 0.90 to 1.18 & 1.04 & 0.91 to 1.18 & 1.25 & 0.99 to 1.58 \\
\hline Model 2, $\mathrm{NO}_{\mathrm{x}}$ & & & & & & & \\
\hline $\begin{array}{l}\text { Per } 10 \mu \mathrm{g} / \mathrm{m}^{3} \\
\text { Model } 1, \mathrm{SO}_{2}\end{array}$ & & 1.03 & 1.00 to 1.07 & 1.02 & 0.99 to 1.06 & 1.05 & 1.01 to 1.09 \\
\hline $0-9.99 \mu \mathrm{g} / \mathrm{m}^{3}$ & 6.78 & 1 (ref) & & & & & \\
\hline $10-19.99 \mu \mathrm{g} / \mathrm{m}^{3}$ & 7.34 & 1.10 & 0.99 to 1.22 & 1.07 & 0.96 to 1.19 & 0.97 & 0.83 to 1.14 \\
\hline $20-29.99 \mu \mathrm{g} / \mathrm{m}^{3}$ & 6.26 & 0.92 & 0.81 to 1.05 & 0.90 & 0.80 to 1.02 & 0.83 & 0.70 to 0.98 \\
\hline $30+\mu \mathrm{g} / \mathrm{m}^{3}$ & 6.51 & 0.95 & 0.84 to 1.08 & 0.98 & 0.86 to 1.10 & 0.82 & 0.66 to 1.02 \\
\hline $\begin{array}{l}\text { Model 2, } \mathrm{SO}_{2} \\
\quad \text { Per } 10 \mu \mathrm{g} / \mathrm{m}^{3}\end{array}$ & & 0.99 & 0.96 to 1.02 & 0.99 & 0.96 to 1.02 & 0.97 & 0.93 to 1.00 \\
\hline
\end{tabular}

Model 1: exposure categorised in four intervals. Model 2: per $10 \mu \mathrm{g} / \mathrm{m}^{3}$ increase in exposure; Cox regression analyses. Adjusted risk ratios are controlled for tobacco smoke exposure, education, and age (age as a continuous variable).

*Both $\mathrm{NO}_{x}$ and $\mathrm{SO}_{2}$ in the regression model.

aRR, adjusted risk ratio; $\mathrm{Cl}$, confidence interval; cRR, crude risk ratio; ref, reference category. 


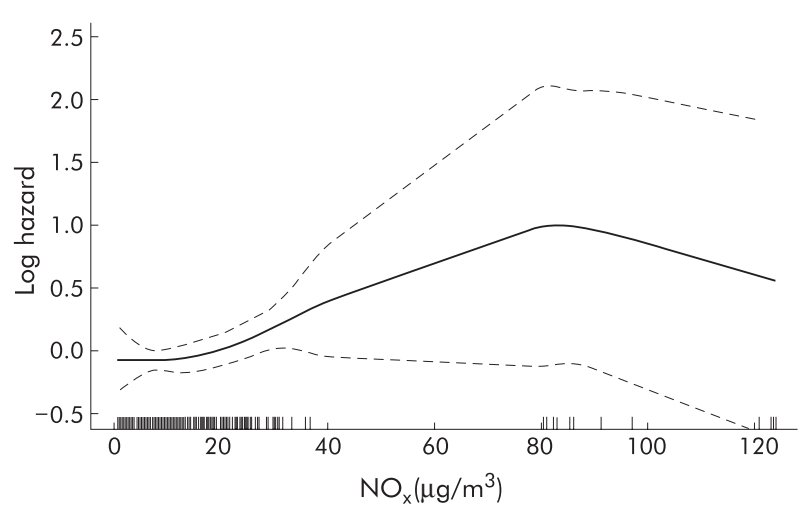

Figure 2 Log hazard of time to lung cancer $v$ the concentration of nitrogen oxides $\left(\mathrm{NO}_{x}\right)$ in the adjusted model. The dashed lines give $95 \%$ confidence limits, and the vertical lines along the $\mathrm{X}$ axis indicate the number of observations. Two extreme $\mathrm{NO}_{x}$ observations with values over $160 \mu \mathrm{g} / \mathrm{m}^{3}$ are excluded from this analysis.

pollution. Smoking at the inclusion was not associated with air pollution exposure, and it seems unlikely that potential changes in smoking habits would be associated with air pollution exposure and thus become a potential confounder.

Other types of cancer were used as competing diagnoses leading to censoring in the Cox regression models. This approach could be questioned, but analyses without this approach gave only marginally stronger associations than those we have presented (data not shown).

The strength of the associations between educational level, smoking, and lung cancer was as expected, ${ }^{9}$ and there was a tendency for the association between cancer and air pollution to be somewhat weaker among heavy smokers than among former or light smokers. A reasonable explanation could be that the extra risk from urban air exposure adds less to the already high risk among heavy smokers. However, the effect of air pollution on lung cancer among participants defined as non-smokers was difficult to evaluate as only a few cases of lung cancer were observed in this group.

Assessing long term exposure to air pollution in urban areas using geographical information systems is well established ${ }^{119-26}$ but has so far seldom been used to assess air pollution exposure in epidemiological studies. ${ }^{11}{ }^{21-26}$ The model used in this study was specified to estimate air pollution levels at individual home addresses in Oslo by historical data on air pollution measurements and emissions, and by meteorological and topographical observations. The available information may be less optimal than more recently collected data. However, the expected long latency between exposure and lung cancer is a strong argument for exploring the association between historical measures of air pollution and lung cancer ${ }^{11}$ —otherwise many years would pass before these relations could be addressed by new cohort studies. Using 1974 to 1978 air pollution exposure in the model ensured a reasonable time sequence between exposure and the development of lung cancer, and maximum statistical power in the analyses. However, the correlation with more recent home address exposure was high and made it difficult to decide if the 1974 to 1978 exposure represented that specific time window, or later or even earlier time windows. To obtain the best results, all available information on air pollution was included in the model. This made it difficult to validate the model, but others have shown reasonable agreement between estimated and measured air pollution levels, especially for $\mathrm{NO}_{\mathrm{x}}$. To use outdoor home address exposure as a measure of total exposure could create misclassification. We assume that this source of misclassification is a larger problem nowadays than it was in the 1974
Table 4 Crude and adjusted risk ratios with 95\% confidence intervals for developing lung cancer among 16209 middle aged men living in Oslo in 1972 with a $10 \mu \mathrm{g} / \mathrm{m}^{3}$ increase in average yearly nitrogen oxides exposure in 1974 to 1978, analysed in different strata of smoking by Cox regression analyses

\begin{tabular}{llll}
\hline & cRR & aRR & $95 \%$ Cl \\
\hline Non-smoker & 1.20 & $* 1.20$ & 0.70 to 2.03 \\
$1-9$ cigarettes/day & 1.24 & 1.25 & 0.98 to 1.58 \\
$10-19$ cigarettes/day & 1.07 & 1.06 & 0.96 to 1.17 \\
$20+$ cigarettes/day & 1.07 & 1.06 & 0.96 to 1.18 \\
† Smoker, amount not & 1.19 & 1.19 & 0.93 to 1.53 \\
reported/former smoker & & &
\end{tabular}

Adjusted risk ratios are controlled for education and age lage as a continuous variable).

*Not adjustment for education (coefficient did not converge).

†The small number of observations make the regression analysis of limited value.

aRR, adjusted risk ratio; $\mathrm{Cl}$, confidence interval; cRR, crude risk ratio.

to 1978 , when middle aged men in Oslo probably spent most of their spare time in their home vicinity and even to a large extent worked there. Furthermore, there are no strong arguments for believing that such misclassification could strengthen the association between air pollution and cancer.

Particulate and sulphate pollution has been found to be associated with lung cancer in some cohort studies. ${ }^{12} 1522$ However, some studies have also found positive associations between nitrogen oxides and lung cancer. ${ }^{11}{ }^{1322} 23$ Misclassification of exposure is an evident limitation in this type of study. ${ }^{2}$ It warrants carefulness in conclusions on causality. ${ }^{35}$ Available measures of air pollutants vary between studies. In the present study we were able to present results from analyses of $\mathrm{SO}_{2}$ and $\mathrm{NO}_{\mathrm{x}}$. Exposure to urban $\mathrm{NO}_{\mathrm{x}}$ or $\mathrm{SO}_{2}$ in the estimated concentrations is unlikely to be a cause of cancer on its own. These agents should therefore be considered as indicators of urban air pollution. Thus there is not necessarily any inconsistency between this study and those showing associations between particulate pollution and lung cancer. $\mathrm{NO}_{\mathrm{x}}$ levels might in fact indicate exposure to particles, carcinogens, or carcinogens bound to particles. The main source of $\mathrm{NO}_{\mathrm{x}}$ in Oslo was emissions from vehicles, while heating was a main source of $\mathrm{SO}_{2}$. The findings therefore favour the view that traffic related air pollution increases the risk of developing lung cancer. The lack of an association between $\mathrm{SO}_{2}$ and lung cancer could have been caused by low $\mathrm{SO}_{2}$ concentrations or by $\mathrm{SO}_{2}$ levels not indicating exposure associated with lung cancer.

Our finding is consistent with those from a case-control study from Sweden with comparable environmental conditions. ${ }^{11}$ A tendency for a strengthening of the association between nitrogen oxides and lung cancer when $\mathrm{SO}_{2}$ data were introduced in the regression model was found in both studies. This finding is difficult to interpret. We speculate that correlation between the estimated concentrations of $\mathrm{NO}_{\mathrm{x}}$ and $\mathrm{SO}_{2}$, and the fact that the modelling of both pollutants is based upon outdoor temperature and wind velocity, could have contributed to this phenomenon, at least in our study. A further argument for this is that the same tendency was seen for other cancers.

\section{Conclusions}

Urban air pollution may increase the risk of developing lung cancer in men. Compared with smoking the association between air pollution and lung cancer is weak but of expected size. However, even population based prospective cohort studies cannot fully exclude the possibility that some 
unknown confounding could affect these findings and they should therefore be confirmed in further cohort studies.

\section{ACKNOWLEDGEMENTS}

The study was supported with grants from the Norwegian Cancer Society and the Norwegian Research Council.

\section{Authors' affiliations}

P Nafstad, B Oftedal, Division of Epidemiology, Norwegian Institute of Public Health, Oslo, Norway

L L Håheim, The Norwegian Centre for Health Technology Assessment, SINTEF Unimed, Oslo

F Gram, Norwegian Institute of Air Research, Kjeller, Norway

I Holme, I Hjermann, P Leren, Unit of Preventive Medicine, Ullevå

University Hospital, Oslo

\section{REFERENCES}

1 Doll R. Atmospheric pollution and lung cancer. Environ Health Perspect 1978;22:23-31.

2 Samet JM, Cohen AJ. Air pollution and lung cancer. In: Holgate S, Koren H, Maynard R, et al, eds. Air pollution and health. London: Academic Press, 1999:841-64.

3 Hemminki K, Pershagen G. Cancer risk of air pollution: epidemiological evidence. Environ Health Perspect 1994;102(suppl 4):187-92.

4 Katsouyanni K, Pershagen G. Ambient air pollution exposure and cancer. Cancer Causes Control 1997;8:284-91.

5 Anonymous. Air toxics from motor vehicles. United States Environmental Protection Agency. 1994 EPA 400-F-92-004. Available from: URL: http:// www.epa.gov/otaq/02-toxic.htm.

6 Cohen AJ, Pope CA. Lung cancer and air pollution. Environ Health Perspect 1995; 103(suppl 8):219-24.

7 Cohen AJ. Outdoor air pollution and lung cancer. Environ Health Perspect 2000; 108(suppl 4):743-50.

8 Doll R, Hill AB. Smoking and carcinoma of the lung. Preliminary report. BMJ 1950;ii:739-48.

9 Engeland A, Andersen A, Haldorsen T, et al. Smoking habits and risk of cancers other than lung cancer: 28 years' follow-up of 26,000 Norwegian men and women. Cancer Causes Control 1996;7:497-506.

10 Samet JM, Eradze GR. Radon and lung cancer risk: taking stock at the millennium. Environ Health Perspect 2000;108(suppl 4):635-41.

11 Nyberg F, Gustavsson P, Jarup L, et al. Urban air pollution and lung cancer in Stockholm. Epidemiology 2000;11:487-95.

12 Dockery DW, Pope CA, Xu X, et al. An association between air pollution and mortality in six US cities. N Engl J Med 1993;329:1753-9.

13 Choi KS, Inoue S, Shinozaki R. Air pollution, temperature, and regional differences in lung cancer mortality in Japan. Arch Environ Health 1997; 52: 160-8

14 Pope CA, Thun MJ, Namboodiri MN, et al. Particulate air pollution as a predictor of mortality in a prospective study of US adults. Am J Respir Crit Care Med 1995;151:669-74.
15 Pope CA Burnett RT, Thun MJ, et al. Lung cancer, cardiopulmonary mortality, and long-term exposure to fine particulate air pollution. JAMA 2002;287:1132-41.

16 Archer VE. Air pollution and fatal lung disease in three Utah counties. Arch Environ Health 1990;45:325-34

17 Biggeri A, Barbone F, Lagazio C, et al. Air pollution and lung cancer in Trieste, Italy: spatial analysis of risk as a function of distance from sources. Environ Health Perspect 1996; 104:750-4.

18 Tango T. Effect of air pollution on lung cancer: a Poisson regression model based on vital statistics. Environ Health Perspect 1994;102:41-5.

19 Health Effects Institute. Update. Spring 2002 p.4. Available from: URL: http://www.healtheffects.org/pubs/UpdQspring02.pdf.

20 Bellander T, Berglind N, Gustavsson P, et al. Using geographic information systems to assess individual historical exposure to air pollution from traffic and house heating in Stockholm. Environ Health Perspect 2001;109:633-9.

21 Mills PK, Abbey D, Beeson WL, et al. Ambient air pollution and cancer in California Seventh-day Adventists. Arch Environ Health 1991;46:271-80.

22 Beeson WL, Abbey DE, Knutsen SF. Long-term concentrations of ambient air pollutants and incident lung cancer in California adults: results from the AHSMOG study. Adventist Health Study on Smog. Environ Health Perspect 1998;106:813-23.

23 Hoek G, Brunekreef B, Goldbohm S, et al. Association between mortality and indicators of traffic-related air pollution in the Netherlands: a cohort study. Lancet 2002:360:1203-9.

24 Langholz B, Ebi KL, Thomas DC, et al. Traffic density and the risk of childhood leukemia in a Los Angeles case-control study. Ann Epidemiol 2002;12:482-7.

25 Reynolds P, Von Behren J, Gunier RB, et al. Traffic patterns and childhood cancer incidence rates in California, United States. Cancer Causes Control 2002; 13:665-73

26 Raaschou-Nielsen $\mathrm{O}$, Hertel $\mathrm{O}$, Thomsen $\mathrm{BL}$, et al. Air pollution from traffic at the residence of children with cancer. Am J Epidemiol 2001; 153:433-43

27 Leren P, Askevold EM, Foss OP, et al. The Oslo study. Cardiovascular disease in middle-aged and young Oslo men. Acta Med Scand 1975:588:1-38.

28 Håheim LL, Holme I, Hjermann I, et al. Smoking habits and risk of fatal stroke: 18 years follow up of the Oslo study. J Epidemiol Community Health 1996;50:621-4.

29 The Cancer Register of Norway. Oslo, Norway: Kreftregisteret, 2000 (in Norwegian).

30 Gram F, Nafstad P, Håheim LL. Annual concentration fields of $\mathrm{SO}_{2}$ and $\mathrm{NO}_{x}$ are calculated for the period 1974-1998 and are used for exposure calculations for 16209 men living in Oslo. J Environ Monit 2003:5:541-6.

31 Henriksen JF, Aas W, Gram F. A risk assessment for damage of cultural heritage influenced by air pollution and climatic parameters. NILU OR 14/ 2001. Kjeller, Norway, 2001 (in Norwegian).

32 Grønskei KE, Gram F, Larssen S. Calculation of dispersion and exposure conditions for some air pollution components in Oslo. NILU OR 8/82 Kjeller, Norway, 1982 (in Norwegian).

33 Insightful. S-PLUS: release 6.0 for Windows. Seattle: Insightful, 2001.

34 Therneau TM, Grambsch PM. Modeling survival data. Extending the Cox model. New York: Springer, 2000.

35 Health Effects Institute. Synopsis of the particle epidemiology reanalysis project http://www.healtheffects.org/Pubs/st-reanalysis.htm. 